\title{
The acute effects of olive oil $v$. cream on postprandial thermogenesis and substrate oxidation in postmenopausal women
}

\author{
M. J. Soares ${ }^{1 *}$, S. J. Cummings ${ }^{2}$, J. C. L. Mamo ${ }^{1}$, M. Kenrick ${ }^{1}$ and L. S. Piers ${ }^{3}$ \\ ${ }^{1}$ Department of Nutrition, Dietetics and Food Science, School of Public Health, Curtin University of Technology, \\ GPO Box U 1987, Perth WA 6845, Australia \\ ${ }^{2}$ Department of Human Movement and Exercise Science, University of Western Australia, 151 Stirling Highway, \\ Perth WA 6009, Australia \\ ${ }^{3}$ Menzies School of Health Research, Tiwi, Northern Territory 0810, Australia and Health Surveillance and \\ Evaluation Section, Department of Human Services, Government of Victoria, Level 18, 120 Spencer Street, \\ Melbourne Victoria 3000, Australia
}

(Received 2 May 2003 - Revised 25 September 2003 - Accepted 10 October 2003)

\begin{abstract}
The influence of the source of dietary fat on postprandial thermogenesis and substrate oxidation rates, was examined in twelve postmenopausal women aged $57-73$ years, with BMI $21.9-38.3 \mathrm{~kg} / \mathrm{m}^{2}$. A single blind, randomised, paired comparison of two high-fat, isoenergetic, mixed test meals was conducted. The major source of fat was either cream (CREAM) or extra virgin olive oil (EVOO). RMR, diet-induced thermogenesis (DIT) and substrate oxidation rates over $5 \mathrm{~h}$ were measured by indirect calorimetry. There were no differences in body weight, RMR, fasting carbohydrate or fat oxidation rates between the two occasions. DIT (EVOO 97 (SD 46 ) v. CREAM 76 (SD 69) $\mathrm{kJ} / 5 \mathrm{~h}$ and EVOO 5.2 (SD 2.5) v. CREAM 4.1 (SD 3.7)\% energy) did not differ between the two test meals. The postprandial increase in carbohydrate oxidation rates, relative to their respective fasting values $(\Delta \mathrm{COX})$, was significantly lower following the EVOO meal (EVOO 10.6 (SD 8.3) v. CREAM 17.5 (SD 10) g/5 h; paired $t$ test, $P=0.023$ ), while postprandial fat oxidation rates $(\triangle \mathrm{FOX}$ ) were significantly higher (EVOO 0.0 (SD 4.4) $v$. CREAM $-3 \cdot 6$ (SD 4.0$) \mathrm{g} / 5 \mathrm{~h} ; P=0.028$ ). In the eight obese subjects, however, DIT was significantly higher following the EVOO meal (EVOO 5.1 (SD 2.0) $v$. CREAM 2.5 (SD 2.9) $\% ; P=0.01$ ). This was accompanied by a significantly lower $\Delta$ COX (EVOO 10.9 (SD 9.9) $v$. CREAM 17.3 (SD 10.5) g/5 h; $P=0.03$ ) and significantly higher $\Delta$ FOX (EVOO $0 \cdot 11$ (SD $4.4) v$. CREAM $-4 \cdot 1$ (SD 4.5$) \mathrm{g} / 5 \mathrm{~h}, P=0.034)$. The present study showed that olive oil significantly promoted postprandial fat oxidation and stimulated DIT in abdominally obese postmenopausal women.
\end{abstract}

Thermogenesis: Fat oxidation: Olive oil: Monounsaturated fatty acid: Obesity: Postmenopausal

The epidemic of obesity, and its co-morbidities of dyslipdaemia, insulin resistance and CVD, is a global problem. All these conditions have nutritional antecedents that are intimately related to the intake of saturated fat. The prevalence of obesity is high in Australia, and is accentuated in the older person (National Health \& Medical Research Council, 1997). Potential metabolic contributors to this age-related increase in fat mass include the observations that older men and women have reduced basal metabolism (Piers et al. 1998), low leptin adjusted for fat mass (Soares et al. 2000) and a low basal rate of fat oxidation (Calles-Escandon et al. 1995). Older women also do not readily increase their fat oxidation to match an increase in fat intake (Melanson et al. 1997), and unlike older men, do not show an association between leptin and fat oxidation (Soares et al. 2000). Moreover, the deficiency of oestrogens at menopause is associated with visceral obesity and a higher incidence of CVD.

Energy balance is determined by macronutrient balance. For most adults in westernised societies, macronutrient balance is a composite of the balances of alcohol, carbohydrate, protein and fat. There is evidence to indicate that, except for fat, these nutrients regulate their respective balances through appropriate changes in their oxidation (Flatt, 1995). Since absorbed fat has only two routes of disposal, storage or oxidation, it is the capacity to oxidise fat that modulates fat balance. Animal studies have demonstrated different rates of weight gain in response to the consumption of different types of dietary fat (Storlien et al. 1998), raising the possibility that fat oxidation may vary with the type of fat. There is now considerable evidence that the type of fat influences its metabolic fate in animals 
and human subjects (Jones et al. 1985, 1992; Jones \& Schoeller, 1988; Clandinin et al. 1995; Bell et al. 1997; DeLany et al. 2000). We have recently tested the influence of the source of fat in isoenergetic breakfast meals in nonobese and mildly obese males (Piers et al. 2002). In that study high-fat test meals included extra virgin olive oil (EVOO) as a source of monounsaturated fat or dairy fat (CREAM) as a source of saturated fatty acids. The results indicated a significantly greater fat oxidation following the EVOO meal, with a significantly lower carbohydrate oxidation over the same time period. The present study was carried out to confirm these effects in postmenopausal women. It was based on the hypothesis that a meal rich in olive oil would promote a greater postprandial oxidation of fat, relative to an isoenergetic meal high in cream.

\section{Subjects}

Twelve postmenopausal women, aged 57-72 years and BMI $21.9-38.3 \mathrm{~kg} / \mathrm{m}^{2}$ who were residents of Perth, Western Australia, were recruited by advertisement in the local media. Subjects were screened by a telephone questionnaire and selected individuals underwent a clinical examination including an electrocardiogram. Inclusion criteria included: (1) absence of clinical signs or symptoms of chronic disease; (2) weight stability ( $\pm 2 \mathrm{~kg}$ for preceding 12 months); (3) not on medication affecting metabolic rate or body composition; (4) resting diastolic blood pressure $<90 \mathrm{mmHg}$; (5) at least 5 years postmenopausal; (6) not on hormone replacement therapy. For details of the physical characteristics of the subjects, see Table 1. All subjects gave written informed consent to participate in the study. The Human Research Ethics Committee of Curtin University of Technology (reference 214/99) approved the protocol. All measurements were made in the clinical rooms of the Bentley Campus of Curtin University, Perth.

\section{Methods}

\section{Study design}

The study was designed as a single-blind randomised comparison of the paired responses to two high-fat isoenergetic meals. The major source of fat was either cream or extra virgin olive oil. The interval between trials was 1-4 weeks, and subjects were instructed to maintain their habitual intake and activity patterns during this period.

Table 1. Physical characteristics of the twelve postmenopausal women

(Mean values and standard deviations)

\begin{tabular}{|c|c|c|c|c|}
\hline & \multicolumn{2}{|c|}{$\begin{array}{l}\text { Entire group } \\
\quad(n \text { 12) }\end{array}$} & \multicolumn{2}{|c|}{$\begin{array}{l}\text { Obese } \\
(n 8)\end{array}$} \\
\hline & Mean & SD & Mean & SD \\
\hline Age (years) & 64 & 4.5 & 65 & $4 \cdot 8$ \\
\hline Weight (kg) & $79 \cdot 3$ & $11 \cdot 6$ & 86 & $4 \cdot 3$ \\
\hline $\operatorname{BMI}\left(\mathrm{kg} / \mathrm{m}^{2}\right)$ & 31.4 & $4 \cdot 8$ & $34 \cdot 4$ & $2 \cdot 3$ \\
\hline Fat mass $(\mathrm{kg})$ & 33.2 & $6 \cdot 5$ & $37 \cdot 6$ & $2 \cdot 9$ \\
\hline Fat-free mass $(\mathrm{kg})$ & $46 \cdot 1$ & $6 \cdot 0$ & $49 \cdot 0$ & 3.5 \\
\hline Waist circumference $(\mathrm{m})$ & 0.940 & 0.109 & 0.998 & 0.074 \\
\hline
\end{tabular}

\section{Test meals}

The CREAM test meal (total weight $293 \mathrm{~g}$, volume $275 \mathrm{ml}$ ) comprised $65 \mathrm{~g}$ natural Swiss muesli (Uncle Toby's, Wahgunyah, Victoria, Australia), $40 \mathrm{~g}$ thickened cream (Peters \& Brownes Group, Balcatta, Perth, Western Australia, Australia) and $188 \mathrm{~g}$ skimmed milk (Peters \& Brownes Group). The EVOO test meal (total weight $276 \mathrm{~g}$, volume $265 \mathrm{ml}$ ) consisted of $66 \mathrm{~g}$ and $195 \mathrm{~g}$ of the same brand of muesli and skimmed milk respectively, with $15 \mathrm{~g}$ extra virgin olive oil ('Olive Grove', Meadow Lea Foods Ltd, Mascot, New South Wales, Australia). The cream was blended with the skimmed milk before being served with the muesli. The olive oil was drizzled on the muesli, warmed under the grill for $2 \mathrm{~min}$, then cooled to room temperature before being served with skimmed milk. The macronutrient content of the two breakfast meals was determined from Australian Food Composition Tables (English \& Lewis, 1991) and manufacturer's product information (Table 2). Subjects were blinded to the fat being consumed. All subjects completed a palatability questionnaire that enquired about amount, taste, oiliness and overall acceptability of each meal. Each answer was scored on a $150 \mathrm{~mm}$ visual analogue scale anchored by the most negative to the most positive response for each question.

\section{Anthropometry and body composition measurements}

Standing height was measured using a stadiometer fixed to the wall and recorded to the nearest $1 \mathrm{~mm}$. Body weight was measured after an overnight fast on each occasion, immediately after voiding, with subjects wearing light indoor clothing and no shoes, on a digital balance and recorded to the nearest $100 \mathrm{~g}$. Mid-arm and waist circumferences were measured as described by Callaway et al. (1988). Body composition was estimated from subcutaneous skinfold thickness measurements at the biceps,

Table 2. Nutrient composition of test meals based on cream (CREAM) and extra virgin olive oil (EVOO)

(Mean values and standard deviations)

\begin{tabular}{|c|c|c|c|c|}
\hline & \multicolumn{2}{|c|}{ CREAM meal } & \multicolumn{2}{|c|}{ EVOO meal } \\
\hline & Mean & SD & Mean & SD \\
\hline $\begin{array}{l}\text { Energy content }(\mathrm{kJ}) \\
\text { Protein }\end{array}$ & 1860 & 22 & 1863 & 24 \\
\hline $\begin{array}{l}\mathrm{g} \\
\% \text { total energy }\end{array}$ & $\begin{array}{l}15 \cdot 5 \\
14\end{array}$ & $\begin{array}{l}0.6 \\
0.4\end{array}$ & $\begin{array}{l}15 \cdot 2 \\
14\end{array}$ & $\begin{array}{l}0.3 \\
0.3\end{array}$ \\
\hline \multicolumn{5}{|l|}{ Total fat } \\
\hline $\begin{array}{l}\mathrm{g} \\
\% \text { total energy }\end{array}$ & $\begin{array}{l}20 \\
40\end{array}$ & $\begin{array}{l}0.7 \\
1.7\end{array}$ & $\begin{array}{l}20 \\
41\end{array}$ & $\begin{array}{l}1.0 \\
1.6\end{array}$ \\
\hline P:S ratio & $2 \cdot 0$ & 0.02 & $3 \cdot 0^{*}$ & 0.02 \\
\hline M:S ratio & $3 \cdot 0$ & 0.02 & $7.0^{*}$ & 0.04 \\
\hline \multicolumn{5}{|l|}{ Carbohydrate } \\
\hline g & 54 & $2 \cdot 1$ & 55 & $1 \cdot 3$ \\
\hline$\%$ total energy & 46 & 1.4 & 47 & $1 \cdot 3$ \\
\hline Sugar $(\mathrm{g})$ & 25 & 0.9 & 24 & 0.5 \\
\hline Starch (g) & 30 & 1.4 & 31 & 0.9 \\
\hline Fibre $(\mathrm{g})$ & 8 & 0.4 & 8 & 0.2 \\
\hline
\end{tabular}

$\mathrm{P}$, polyunsaturated fatty acid; $\mathrm{S}$, saturated fatty acid; $\mathrm{M}$, monounsaturated fatty acid.

Mean values were significantly different from those of the CREAM meal (paired $t$ test): ${ }^{*} P<0.005$. 
triceps, subscapular and suprailiac sites as described by Durnin \& Womersley (1974). All measurements were made in triplicate and the average was used in the equations of Durnin and Womersley for the sum of four skinfold thicknesses. In one subject, estimates of body composition were based on the sum of biceps and triceps skinfold thicknesses only, as measurements at the other two sites were beyond the limits of the callipers.

\section{Measurement protocol}

Subjects were requested to abstain from any strenuous exercise for $36 \mathrm{~h}$ before the measurement. Subjects arrived at the laboratory after a minimum of $8 \mathrm{~h}$ sleep, and kept physical activity to a minimum. On arrival subjects were asked to empty their bladder after which they were weighed. They lay supine for a mandatory $30 \mathrm{~min}$ rest period, while the calorimeter $\left(\mathrm{V}_{\max }-29\right.$ metabolic monitor; Sensor Medics, Yorba Linda, CA, USA) was calibrated. At the end of this rest period, the canopy of the calorimeter was placed over the head of the subject and they were asked to remain awake and as motionless as far as possible in a supine position. Two $15 \mathrm{~min}$ RMR measurements were made, with a 10 min interval between measurements. The initial $5 \mathrm{~min}$ of each measurement period was discarded from the analysis. Our previous studies indicate that this protocol yields an RMR not significantly different from BMR measured immediately on waking following an overnight stay in the laboratory (Soares et al. 1989).

After the RMR measurement, the plastic canopy was removed and subjects made a fasting collection of urine. They were given a breakfast meal (Table 2), which they consumed within $10 \mathrm{~min}$. A palatability questionnaire, based on a $150 \mathrm{~mm}$ visual analogue scale, was completed in this period. In between measurements, subjects were allowed to sit up in bed and listen to music or read. Some elected to sit at a table close to the bed, where they did craftwork, needlework or solved crosswords. Thirty-five minutes into each postprandial hour, subjects returned to the supine position and rested for $10 \mathrm{~min}$. The canopy was then placed over the head and measurements made for the last $15 \mathrm{~min}$ of the hour. The first $5 \mathrm{~min}$ was not included in subsequent data analysis. At the end of the energy expenditure measurements $(5 \mathrm{~h}$ after the breakfast meal), subjects were asked to void again. The two urine collections were made in separate containers. The volume and duration of collection was noted, and a portion was frozen. Total urinary $\mathrm{N}$ excretion was estimated by the Kjeldahl technique. All subjects were offered a light lunch before they returned home.

\section{Resting metabolic rate}

RMR was measured by indirect calorimetry using the $\mathrm{V}_{\text {max }}-29$ metabolic monitor (Sensor Medics): an open-circuit ventilated canopy measurement system. The measurement was conducted under standardised conditions, as in our previous studies (Soares et al. 1989; Piers et al. 1992) with subjects lying: (1) at complete physical rest; (2) in a thermally neutral environment; (3) 12-14 h after their last meal and a minimum of $8 \mathrm{~h}$ of sleep; (4) awake and emotionally undisturbed; (5) without disease and fever. The within-subject CV in RMR, separated from measurement error, was $1.0 \%$ in the present study.

The $\mathrm{V}_{\max }-29$ (Sensor Medics) was calibrated on the morning of each experimental day using a two-point calibration based on two separate mixtures of known gas content. Flow calibrations were achieved using a calibrated 3 litre syringe as directed in the manufacturer's instructions. Flow rate on each measurement day was set at $401 / \mathrm{min}$. On each experimental day, the instrument was re-calibrated for flow and the analysers for drift $2 \mathrm{~h}$ after ingestion of the test meal. Performance of the instrument was also checked at regular intervals during the study period by monitoring the $\mathrm{CO}_{2}$ produced: $\mathrm{O}_{2}$ consumed during $30 \mathrm{~min}$ ethanol burns. The mean ratio for twenty ethanol burns was 0.668 (SD 0.016) with CV $2.3 \%$.

\section{Diet-induced thermogenesis}

Diet-induced thermogenesis (DIT) was measured as described previously (Piers et al. 1992, 2002) and expressed in absolute values $(\mathrm{kJ} / 5 \mathrm{~h})$ and as \% energy in the breakfast meal.

\section{Substrate oxidation rates}

Whole-body substrate oxidation rates were calculated at rest (fasting), and for every hour up to $5 \mathrm{~h}$ postprandial, using measures of $\mathrm{O}_{2}$ consumption, $\mathrm{CO}_{2}$ production and urinary $\mathrm{N}$ excretion in the postprandial phase. The equations of Ferrannini (1988) were used to calculate energy expenditure and substrate oxidation rates.

\section{Statistical analysis}

All results are presented as mean values and standard deviations, unless otherwise stated. Pearson's correlation coefficients for all anthropometric, body composition and metabolic variables were separately calculated for each meal type. Changes between fasting and fed states were calculated by subtracting the fasting value $\times$ duration of measurement from the total postprandial value over $5 \mathrm{~h}$. Since the intervals of measurement in the postprandial period were equal, this summary statistic was analogous to determining the incremental area under the curve (Mathews et al. 1990). Paired $t$ tests were used to compare the change in metabolic variables of interest. A repeatedmeasures ANOVA with order of meals as between-subject factor was also used. Statistical significance was accepted at the $5 \%$ level. Data were analysed using the SPSS for Windows (version 11; SPSS Inc., Chicago, IL, USA) statistical software package.

\section{Results}

There was no significant difference in body weight, fat mass or fat-free mass on the two occasions. The nutrient composition of the test meals is shown in Table 2. The EVOO meal had significantly higher monounsaturated: saturated fatty acids ratio as well as polyunsaturated:saturated fatty acids ratio (Table 2). There was no difference 
in the results of the sensory evaluation of the test meals for the scores for 'amount' (CREAM 94 (SD 18) v. EVOO 91 (SD 28) mm), 'taste' (CREAM 104 (SD 34) v. EVOO 99 (SD 34) mm), 'oiliness' (CREAM 57 (SD 40) v. EVOO 60 (SD 48) mm) and 'overall acceptability' (CREAM 105 (SD 40) v. EVOO 100 (SD 42) $\mathrm{mm}$ ) of each meal.

\section{Effect of breakfast meals}

There were no differences in resting metabolic variables (Table 3). DIT, in absolute terms (kJ/5 h) or as \% energy in meal, was not different between test meals (Table 3). There was a significant rise in RER following both meals. However, the change in RER was significantly
$(P=0.018)$ lower following the EVOO meal (Table 3, Fig. 1). Postprandial protein oxidation rates were significantly lower following both meals, but the incremental change in protein oxidation was not different between test meals (Table 3). Carbohydrate oxidation was significantly $(P=0.023)$ lower following the EVOO meal as compared with the CREAM meal (Table 3). Postprandial fat oxidation was significantly suppressed following the CREAM meal (Table 3), but not after the EVOO meal. Hence change in fat oxidation was significantly $(P=0.028)$ greater following the EVOO meal. An ANOVA for repeated measures, with order of meals as between-subject factor, provided the same statistical outcomes for each variable tested (results not shown).

Table 3. The influence of the source of fat on postprandial thermogenesis and substrate oxidation measured over $5 \mathrm{~h}$ in postmenopausal women*

(Mean values and standard deviations for twelve subjects)

\begin{tabular}{|c|c|c|c|c|c|}
\hline & \multicolumn{2}{|c|}{ CREAM meal } & \multicolumn{2}{|c|}{ EVOO meal } & \multirow{2}{*}{$\begin{array}{l}\text { Statistical significance } \\
\text { of effect: } P \text { value for } \\
\text { paired difference } †\end{array}$} \\
\hline & Mean & SD & Mean & SD & \\
\hline \multicolumn{6}{|l|}{ Fasting } \\
\hline RMR $(k J / h)$ & 210 & 29 & 208 & 30 & 0.52 \\
\hline RER & 0.85 & 0.046 & 0.86 & 0.038 & 0.33 \\
\hline Protein oxidation $(\mathrm{g} / \mathrm{h})$ & $3 \cdot 1$ & 0.90 & $2 \cdot 9$ & 0.69 & 0.70 \\
\hline Fat oxidation $(\mathrm{g} / \mathrm{h})$ & 1.80 & 1.03 & 1.60 & 0.80 & 0.36 \\
\hline Carbohydrate oxidation $(\mathrm{g} / \mathrm{h})$ & $5 \cdot 4$ & $2 \cdot 19$ & $6 \cdot 0$ & 1.96 & 0.29 \\
\hline \multicolumn{6}{|l|}{ Meal-induced changes } \\
\hline \multicolumn{6}{|l|}{ Diet-induced thermogenesis } \\
\hline $\mathrm{kJ} / 5 \mathrm{~h} \ddagger$ & $76 \cdot 0$ & 69 & 97 & 46 & 0.22 \\
\hline \% Energy intake§ & $4 \cdot 1$ & 3.68 & $5 \cdot 2$ & $2 \cdot 45$ & 0.23 \\
\hline Change in RER $\ddagger$ & 0.055 & 0.039 & 0.025 & 0.036 & 0.018 \\
\hline Change in protein oxidation $(\mathrm{g} / 5 \mathrm{~h}) \ddagger$ & -3.2 & $5 \cdot 0$ & -4.0 & 3.74 & 0.59 \\
\hline Change in carbohydrate oxidation $(\mathrm{g} / 5 \mathrm{~h}) \ddagger$ & $17 \cdot 5$ & 10 & $10 \cdot 6$ & $8 \cdot 3$ & 0.023 \\
\hline Change in fat oxidation $(\mathrm{g} / 5 \mathrm{~h}) \ddagger$ & -3.6 & 4.0 & 0.0 & 4.4 & 0.028 \\
\hline
\end{tabular}

* For details of subjects, diets and procedures, see Tables 1 and 2 and p. 246.

+ Similar statistical effects were obtained when analysed by repeated-measures ANOVA with order of meals as between-subject factor. $\ddagger$ Calculated as postprandial values over $5 h-($ fasting value per $h \times 5$ ).

$\S$ Calculated as (postprandial values over $5 \mathrm{~h}-($ (fasting value per $\mathrm{h} \times 5)$ )/energy intake) $\times 100$

CREAM, cream; EVOO, extra virgin olive oil.
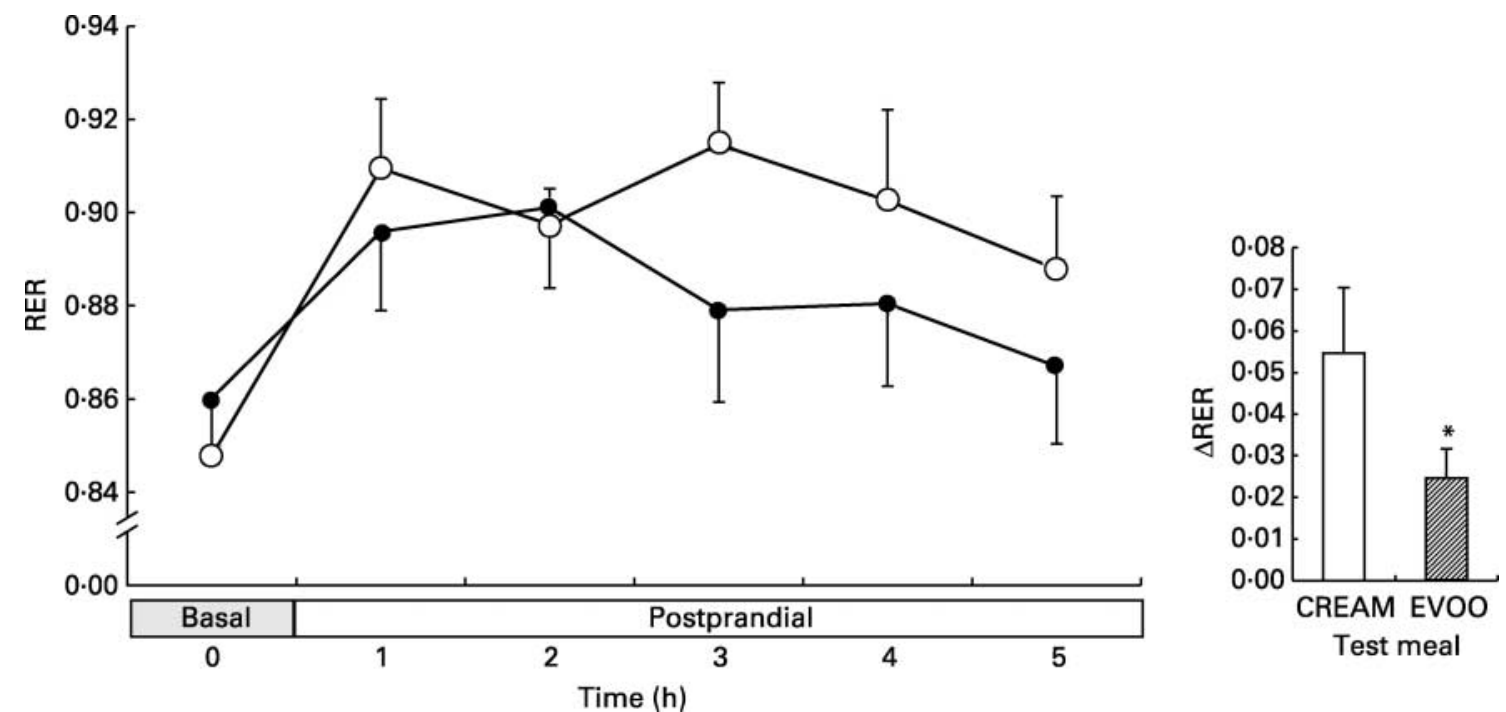

Fig. 1. Basal (fasting) and postprandial RER in twelve postmenopausal women, following meals high in cream (CREAM, $O)$ or extra-virgin olive oil (EVOO, $\bullet$ ). For details of subjects, diets and procedures, see Tables 1 and 2 and p. 246. Values are means with their standard errors shown by vertical bars. Mean value was significantly different from that of the CREAM meal (paired $t$ test): * $P<0 \cdot 018$. 
Correlation coefficients for body composition variables and indices of thermogenesis as well as substrate oxidation were computed for each test meal separately. They did not reveal any significant results. The only relationship of note was the inverse trend between BMI and DIT $(r-0.56$, $P=0.06)$ following the CREAM meal, which was not evident after the EVOO meal $(r-0 \cdot 13, P=0 \cdot 69)$. To examine whether EVOO had a different effect in the obese, a subanalysis was conducted. DIT was significantly increased in the obese following EVOO (Table 4, Fig. 2). There was a significantly lower incremental change in carbohydrate oxidation and reciprocally, a greater incremental change in fat oxidation following EVOO (Table 4).

\section{Discussion}

Stable isotope studies in human subjects indicate that differences in fatty acid oxidation stem from differences in chain length, degree of unsaturation and the position and stereoisomeric configuration of double bonds (DeLany et al. 2000). Medium-chain fatty acids such as laurate $(2: 0)$ were more readily oxidized than long-chain

Table 4. Changes in diet-induced thermogenesis and substrate oxidation in obese postmenopausal women following mixed test meals with different sources of fat ${ }^{*}$

(Mean values and standard deviations for eight subjects)

\begin{tabular}{|c|c|c|c|c|c|}
\hline & \multicolumn{2}{|c|}{ CREAM meal } & \multicolumn{2}{|c|}{ EVOO meal } & \multirow{2}{*}{$\begin{array}{l}\text { Statistical significance } \\
\text { of effect: } P \text { value for } \\
\text { paired difference† }\end{array}$} \\
\hline & Mean & SD & Mean & SD & \\
\hline \multicolumn{6}{|l|}{ Fasting } \\
\hline RMR (kJ/h) & 222 & $26 \cdot 4$ & 219 & $28 \cdot 2$ & 0.43 \\
\hline RER & 0.84 & 0.044 & 0.85 & 0.035 & 0.50 \\
\hline Protein oxidation $(\mathrm{g} / \mathrm{h})$ & $3 \cdot 2$ & 0.98 & $3 \cdot 1$ & 0.75 & 0.90 \\
\hline Fat oxidation $(\mathrm{g} / \mathrm{h})$ & $2 \cdot 00$ & 1.08 & 1.70 & 0.75 & 0.44 \\
\hline Carbohydrate oxidation $(\mathrm{g} / \mathrm{h})$ & 5.5 & $2 \cdot 19$ & $6 \cdot 1$ & 2.08 & 0.46 \\
\hline \multicolumn{6}{|l|}{ Meal-induced changes } \\
\hline \multicolumn{6}{|l|}{ Diet-induced thermogenesis } \\
\hline $\mathrm{kJ} / 5 \mathrm{~h} \ddagger$ & $46 \cdot 0$ & 53 & 95 & 37 & 0.009 \\
\hline$\%$ Energy intake§ & $2 \cdot 5$ & $2 \cdot 86$ & $5 \cdot 1$ & 2.00 & 0.01 \\
\hline Change in RER $\ddagger$ & 0.055 & 0.042 & 0.023 & 0.039 & 0.016 \\
\hline Change in protein oxidation $(\mathrm{g} / 5 \mathrm{~h}) \ddagger$ & -3.4 & 5.78 & -4.6 & $2 \cdot 68$ & 0.59 \\
\hline Change in carbohydrate oxidation $(\mathrm{g} / 5 \mathrm{~h}) \ddagger$ & $17 \cdot 3$ & $10 \cdot 48$ & $10 \cdot 9$ & 9.87 & 0.030 \\
\hline Change in fat oxidation $(\mathrm{g} / 5 \mathrm{~h}) \ddagger$ & -4.1 & 4.54 & $0 \cdot 11$ & 4.45 & 0.034 \\
\hline
\end{tabular}

CREAM, cream; EVOO, extra virgin olive oil.

${ }^{*}$ For details of subjects, diets and procedures, see Tables 1 and 2 p. 246.

† Similar statistical effects were obtained when analysed by repeated measures ANOVA with order of meals as between-subject factor.

$\ddagger$ Calculated as postprandial values over $5 \mathrm{~h}-$ (fasting value per $\mathrm{h} \times 5$ ).

$\S$ Calculated as ((postprandial values over $5 \mathrm{~h}-($ fasting value per $\mathrm{h} \times 5)) /$ energy intake $) \times 100$
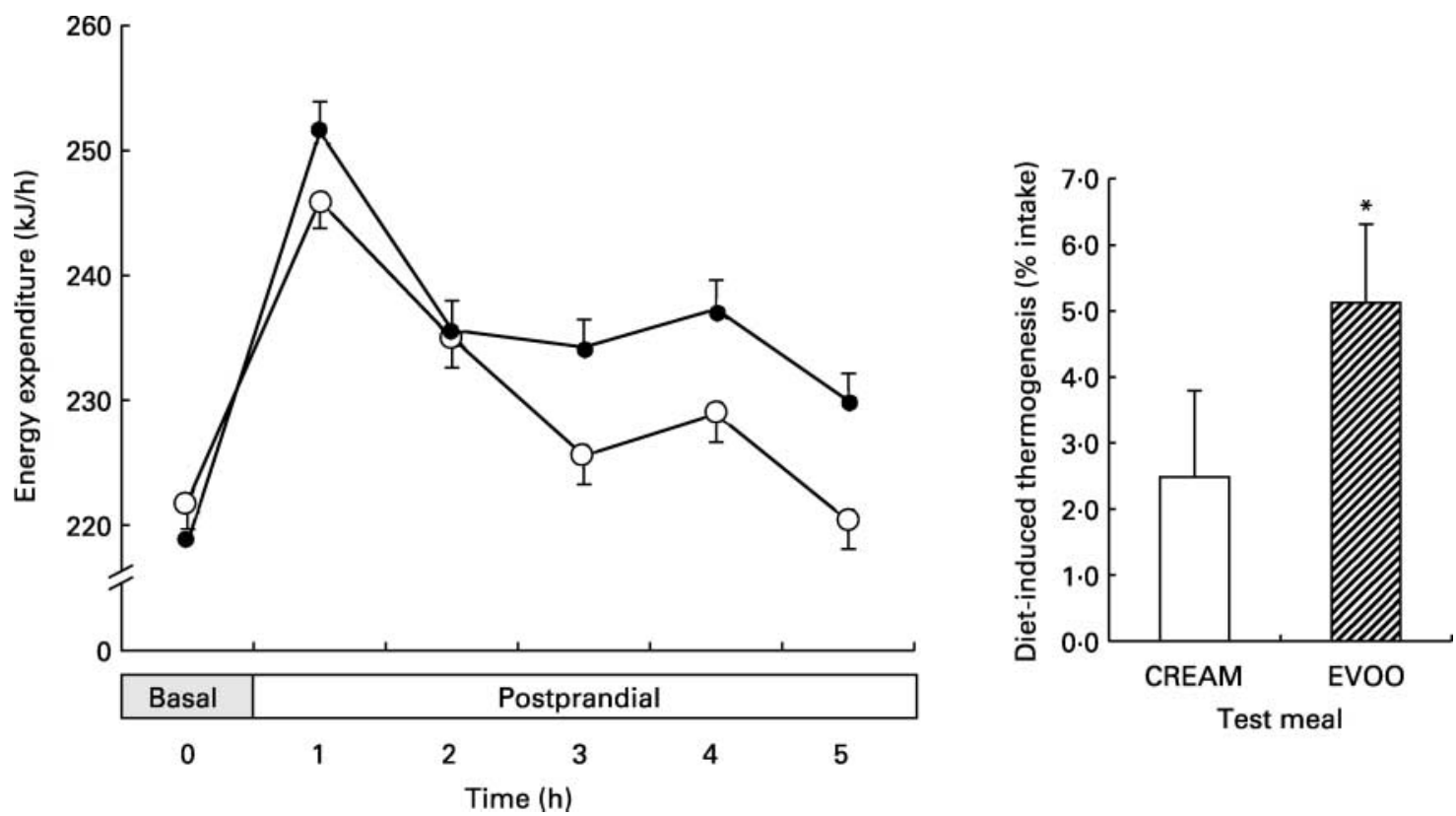

Fig. 2. Basal (fasting) and postprandial energy expenditure in eight obese postmenopausal women, following meals high in cream (CREAM, 0 ) or extra virgin olive oil (EVOO, ). For details of subjects, diets and procedures, see Tables 1 and 2 and p. 246 . Values are means with their standard errors shown by vertical bars. Mean value was significantly different from that of the CREAM meal (paired $t$ test): ${ }^{\star} P<0.01$. 
saturated fatty acids, and unsaturated fatty acids were more readily oxidized than saturated fatty acids (DeLany et al. 2000). Jones et al. (1985) demonstrated that when chain length was similar, oleic acid was oxidised more readily than both stearic and linoleic (oxidation ratio oleic: linoleic: stearic $14 \cdot 0: 4.5: 1 \cdot 0)$. Since the source of fat determines the eventual mix of fatty acids in the diet, we used a whole-food approach to alter the fatty acid milieu. The nutrient composition of the test meals used showed that they were similar in their energetic value, macronutrient composition, sugar, starch and fibre content. EVOO has a high monounsaturated fatty acid content, and relative to CREAM, is a better source of polyunsaturated fatty acids. Hence, the exclusive use of EVOO resulted in a significant increase in dietary monounsaturated:saturated fatty acid ratio and a smaller but significant increase in the polyunsaturated:saturated fatty acid ratio. The effects on postprandial thermogenesis and substrate oxidation in the present study have therefore been ascribed to EVOO, rather than a specific fatty acid.

\section{Olive oil, fat oxidation and thermogenesis}

The results showed that the postprandial increase in RER was less following EVOO, suggesting a greater oxidation of fat relative to carbohydrate (Fig. 1). Calculation of substrate oxidation rates showed that the increase in carbohydrate oxidation was attenuated following the EVOO meal. Correspondingly, fat oxidation was significantly suppressed after the CREAM meal but showed no change following EVOO (Table 3). The incremental change in fat oxidation was significantly greater after EVOO (Table 3). The time course of these changes indicates that maximum suppression occurred 3-5 h after meal ingestion (Fig. 1), a period that coincides with the time for fat digestion and absorption. Similar observations in our earlier study (Piers et al. 2002), suggest that the prevailing mix of fatty acids has significant effects on substrate oxidation in the late postprandial state.

DIT is the result of energy expended to digest, transport, metabolise and store food. It averages about $10 \%$ total daily energy expenditure and varies with the metabolic fate of the ingested substrate (Segal \& Gutin, 1983). The significant effects of EVOO on whole-body substrate oxidation were not accompanied by statistical differences in DIT. Our subjects ranged in BMI from lean to grade 2 obese. There is evidence to suggest that obese individuals, and those predisposed to obesity, may have a defective thermogenic response to meal ingestion when compared with lean individuals (Raben et al. 1994; Napoli \& Horton, 1996; Matsumoto et al. 2001). De Jonge \& Bray (1997) concluded that DIT was lower in obesity, an outcome demonstrated in twenty-two of twenty-nine studies examined. In the present study we found a trend for BMI to be inversely related to DIT $(r-0 \cdot 56, P=0 \cdot 06)$ following CREAM. This would support the notion that obesity is associated with a lower DIT. However, a similar correlation was not seen after EVOO. This raised the possibility that EVOO either stimulated thermogenesis in obese subjects or suppressed it in lean subjects. Our small sample size did not allow a statistically meaningful comparison to be made between lean and obese. Instead, we re-examined the responses only in the obese. The analysis indicated that dietary thermogenesis was greater by almost $60 \%$ following the EVOO test meal (Fig. 2). This enhanced thermogenesis was accompanied by significant changes in both carbohydrate and fat oxidation. The obese women in the present study also had high waist circumferences $(>0.88 \mathrm{~m}$, Table 1). Previously, we had demonstrated that the DIT response to EVOO was significantly greater in men with a high, compared with a low, waist circumference (Piers et al. 2002). Overall, the results suggest that EVOO may be particularly beneficial to obese individuals with visceral adiposity.

\section{Potential mechanisms}

Differences in DIT, and in substrate utilisation, could potentially arise from differences in gastric events. Accordingly, a faster gastric emptying would result in an earlier rise to peak as well as a quicker descent to baseline. The DIT responses to the two test meals did not have this pattern when either the total results (not shown) or the results from obese subjects were viewed (Fig. 2). Differences in RER and DIT instead appeared at $3-5 \mathrm{~h}$ postprandial, a time point beyond gastric events (Figs 1 and 2). Robertson et al. (2002) used more direct techniques. They studied the effects of different types of fat on gastric emptying, based on the excretion in breath of $\left[{ }^{13} \mathrm{C}\right]$ octanoic acid in the meal. They concluded that there were no differences in gastric emptying between saturated and monounsaturated mixed meals.

Changes in fatty acid intake will alter membrane phospholipid composition, and hence influence the metabolic fate of ingested macronutrients. However, changes in membrane composition are more likely with chronic dietary manipulation rather than with acute changes in fatty acid supply, and hence are unlikely to explain the current observations.

The role of the sympathetic nervous system may be important to the results documented here (Fagius \& Berne, 1994). There is evidence for a reduced sympathetic nervous system activity in the aetiology of obesity in animals and man (Bray, 1990; Matsumoto et al. 2001). While all macronutrients stimulate the sympathetic nervous system (Fagius \& Berne, 1994), the type of dietary fat has important influences as well (Young \& Walgren, 1994). Takeuchi et al. (1995) and Matsuo et al. (1995) have demonstrated a lower sympathetic activity and low DIT, but a higher carcass fat content in rats fed beef tallow (saturated fat) as compared with safflower oil (unsaturated fat). Importantly, sympathectomy abolished the differences in body fat accumulation and DIT between the two dietary fat groups.

Femoral and gluteal fat cells have a lower lipolytic response to catecholamines than abdominal adipocytes. The latter have an increased $\beta$-adrenoceptor density and sensitivity and reduced $\alpha$-adrenoceptor affinity and number (Bouchard et al. 1993). Abdominally obese individuals could hence be more responsive to stimulation by the sympathetic nervous system. This would explain our current observations of a higher DIT and greater fat utilisation 
following EVOO in abdominally obese postmenopausal women. If it is surmised that similar mechanisms operate during chronic feeding of olive-oil-based diets, then the results of Walker et al. (1996) are important. These authors have shown a greater mobilisation of upper body fat (abdominal) than lower body (gluteo-femoral) fat, following a high-olive-oil weight-reducing diet in subjects with type 2 diabetes. Additional support is provided by our recent results from an ad libitum 4-week dietary intervention study. A predominantly high-olive-oil diet resulted in lower \% body fat and lower waist: hip ratios, compared with a saturated fat diet at equivalent intakes of total fat (Piers et al. 2003). Overall, the sympathetic nervous system could play an important role in mediating the effects of a high-EVOO meal.

The PPAR provide a molecular mechanism for the modulation of lipid homeostasis by dietary fatty acids, and are a plausible pathway for our observations (Kliewer et al. 1997; Fruchart et al. 1999; Clarke et al. 2002). $\operatorname{PPAR} \alpha$ activation, in particular, is rapid and occurs within the postprandial phase. PPAR $\alpha$ serves to suppress genes encoding proteins of lipid synthesis, while inducing genes encoding proteins of fatty acid oxidation and thermogenesis (Clarke et al. 2002). The monounsaturated and polyunsaturated fatty acid (n-6) content of the EVOO meal was higher than the CREAM meal (Table 2), and both types of fatty acids are more effective in stimulating PPAR $\alpha$ than are saturated fatty acids (Clarke et al. 2002).

In conclusion, our present study provides additional evidence that the isoenergetic substitution of cream with olive oil results in an alteration in postprandial substrate oxidation rates. This is manifested as a lesser postprandial increase in carbohydrate oxidation, and a lack of suppression of postprandial fat oxidation following EVOO. The observation that EVOO stimulated DIT in the abdominally obese would auger well for olive-oil-based dietary interventions targeting the management of obesity and the metabolic syndrome.

\section{Acknowledgements}

M. J. S. and J. C. L. M. acknowledge grants from Curtin University and Peters \& Brownes Group respectively. L. S. P. was supported by a grant from the National Health and Medical Research Council (981019). The authors thank the volunteers for their cooperation during the study, and the referees of this paper for their very helpful comments.

\section{References}

Bell RR, Spencer MJ \& Sherriff JL (1997) Voluntary exercise and monounsaturated canola oil reduce fat gain in mice fed diets high in fat. $J$ Nutr 127, 2006-2010.

Bouchard C, Despres JP \& Mauriege P (1993) Genetic and nongenetic determinants of regional fat distribution. Endocr Rev 14, 72-93.

Bray GA (1990) Obesity - a state of reduced sympathetic activity and normal or high adrenal activity (the autonomic and adrenal hypothesis revisited). Int $J$ Obes Relat Metab Disord $\mathbf{1 4}$ 77-92.

Callaway CW, Chumlea WC, Bouchard C, et al. (1988) Circumferences. In Anthropometric Standardisation Reference Manual, pp. 39-54 [TG Lohman, AF Roche and R Martorell, editors]. Champaign, IL: Human Kinetics Books.

Calles-Escandon J, Arciero PJ, Gardner AW, Bauman C \& Poehlman ET (1995) Basal fat oxidation decreases with ageing in women. J App Physiol 78, 266-271.

Clandinin MT, Wang LC, Rajotte RV, et al. (1995) Increasing the dietary polyunsaturated fat content alters whole-body utilization of 16:0 and 10:0. Am J Clin Nutr 61, 1052-1057.

Clarke SD, Gasperikova D, Nelson C, Lapillonne A \& Heird WC (2002) Fatty acid regulation of gene expression. A genomic explanation for the benefits of the Mediterranean diet. Ann NY Acad Sci 967, 283-298.

de Jonge L \& Bray GA (1997) The thermic effect of food and obesity: a critical review. Obes Res 5, 622-631.

DeLany JP, Windhauser MM, Champagne CM \& Bray GA (2000) Differential oxidation of individual dietary fatty acids in humans. Am J Clin Nutr 72, 905-911.

Durnin JGVA \& Womersley J (1974) Body fat assessed from total body density and its estimation from skinfold thickness: measurements on 481 men and women aged 16 to 72 years. Br J Nutr 32, 77-97.

English R \& Lewis J (1991) Nutritional Values of Australian Foods. Canberra: Australian Government Printing Service.

Fagius J \& Berne C (1994) Increase in muscle sympathetic activity in humans after food intake. Clin Sci 86, 159-167.

Ferrannini E (1988) The theoretical bases of indirect calorimetry: a review. Metab Clin Exp 37, 287-301.

Flatt JP (1995) Use and storage of carbohydrate and fat. Am J Clin Nutr 61, Suppl. 4, 952S-959S.

Fruchart JC, Duriez P \& Staels B (1999) Peroxisome proliferatoractivated receptor-alpha activators regulate genes governing lipoprotein metabolism, vascular inflammation and atherosclerosis. Curr Opin Lipidol 10, 245-257.

Jones PJ, Pencharz PB \& Clandinin MT (1985) Whole body oxidation of dietary fatty acids: implications for energy utilization. Am J Clin Nutr 42, 769-777.

Jones PJ, Ridgen JE, Phang PT \& Birmingham CL (1992) Influence of dietary fat polyunsaturated to saturated ratio on energy substrate utilization in obesity. Metab Clin Exp 41, 396-401.

Jones PJ \& Schoeller DA (1988) Polyunsaturated: saturated ratio of diet fat influences energy substrate utilization in the human. Metab Clin Exp 37, 145-151.

Kliewer SA, Sundseth SS, Jones SA, et al. (1997) Fatty acids and eicosanoids regulate gene expression through direct interactions with peroxisome proliferator-activated receptors alpha and gamma. Proc Natl Acad Sci 94, 4318-4323.

Mathews JN, Altman DG, Campbell MJ \& Royston P (1990) Analysis of serial measurements in medical research. $\mathrm{Br}$ Med $J$ 300, 230-235.

Matsumoto T, Chiemi M, Ue H, et al. (2001) Comparison of thermogenic sympathetic responses to food intake between obese and non-obese young women. Obes Res 9, 78-85.

Matsuo T, Shimomura Y \& Saitoh S, et al. (1995) Sympathetic activity is lower in rats fed a beef tallow diet than in rats fed a safflower oil diet. Metabolism 44, 934-939.

Melanson KJ, Saltzman E, Russell RR \& Roberts SB (1997) Fat oxidation in response to four graded energy challenges in young and older women. Am J Clin Nutr 66, 860-866.

Napoli R \& Horton ES (1996) Energy requirements. In Present Knowledge in Nutrition, 7th ed., pp. 1-6 [EE Ziegler and LJ Filer Jr, editors]. Washington, DC: ILSI Press.

National Health and Medical Research Council (1997) Acting on 
Australia's Weight: A Strategic Plan for the Prevention of Overweight and Obesity. Canberra: Australian Government Publishing Service.

Piers LS, Soares MJ, McCormack LM \& O'Dea K (1998) Is there evidence for an age-related reduction in metabolic rate? $J$ Appl Physiol 85, 2196-2204.

Piers LS, Soares MJ, Makan T \& Shetty PS (1992) Thermic effect of a meal. 1. Methodology and variation in normal young adults. Br J Nutr 67, 165-175.

Piers LS, Walker KZ, Stoney RM, Soares MJ \& O’Dea K (2002) The influence of the type of dietary fat on postprandial fat oxidation rates: monounsaturated (olive oil) vs saturated fat (cream). Int J Obes Relat Metab Disord 26, 814-821.

Piers LS, Walker KZ, Stoney RM, Soares MJ \& O’Dea K (2003) Substitution of saturated with monounsaturated fat in a 4-week diet affects body weight and composition of overweight and obese men. Br J Nutr 90, 717-727.

Raben A, Anderson HB, Christensen NJ, et al. (1994) Evidence for an abnormal postprandial response to a high fat meal in women predisposed to obesity. Am J Physiol 267, E549-E559.

Robertson MD, Jackson KG, Fielding BA, Morgan LM \& Williams CM (2002) Acute ingestion of a meal rich in $n-3$ polyunsaturated fatty acids results in rapid gastric emptying in humans. Am J Clin Nutr 76, 232-238.
Segal KK \& Gutin B (1983) Thermic effects of food and exercise in lean and obese women. Metab Clin Exp 32, 581-588.

Soares MJ, Piers LS, Kraai L \& Shetty PS (1989) Day-to-day variations in basal metabolic rates and energy intakes of human subjects. Eur J Clin Nutr 43, 465-472.

Soares MJ, Piers LS, O'Dea K \& Collier GR (2000) Plasma leptin concentrations, basal metabolic rates and respiratory quotients in young and older adults. Int J Obes 24, 1592-1599.

Storlein LH, Hulbert AJ \& Else PL (1998) Polyunsaturated fatty acids, membrane function and metabolic diseases such as diabetes and obesity. Curr Opin Clin Nutr Metab Care 1, 559-563.

Takeuchi H, Matsuo T, Tokuyama K, Shimomura Y \& Suzuki M (1995) Diet-induced thermogenesis is lower in rats fed a lard diet than in those fed a high oleic acid safflower oil diet, a safflower oil diet or a linseed oil diet. J Nutr 125, 920-925.

Walker KZ, O’Dea K, Johnson L, et al. (1996) Body fat distribution and non-insulin-dependent diabetes: comparison of a fiber-rich, high-carbohydrate, low-fat $(23 \%)$ diet and a $35 \%$ fat diet high in monounsaturated fat. Am J Clin Nutr 63, 254-260.

Young JB \& Walgren MC (1994) Differential effects of dietary fats on sympathetic nervous system activity in the rat. Metab Clin Exp 43, 51-60. 